\title{
Epstein's TARGET Framework and Motivational Climate in Sport: Effects of a Field-Based, Long-Term Intervention Program
}

\section{Jose A. Cecchini', Javier Fernandez-Rio', Antonio Mendez-Gimenez ${ }^{1}$, Christian Cecchini $^{2}$ and Laura Martins ${ }^{3}$}

1 University of Oviedo, Faculty of Teacher Training and Education, Department of Educational Sciences, c) Aniceto Sela s/n despacho 205, 33005, Oviedo, Asturias, Spain

E-mail: cecchini@uniovi.es

2Louisiana School for Math Science \& the Arts. 715 University Parkway, Natchitoches, LA, USA

${ }^{3}$ Louisiana State University. Department of Foreign Languages \& Literatures. 316 Hodges Hall. Baton Rouge, LA 70803, USA

e-mail: martins@|su.edu

\begin{abstract}
The aim of this study was to assess the long-term effects that the manipulation of the motivational climate can produce on social factors, psychological mediators, motivation and behavioural consequences. 283 student-athletes with ages ranging from 14 to 18 years $(M=13,54 \pm 1,31)$ completed a questionnaire that included the BPNES, the PLOC, the subscales cooperative learning and improvement of the PMCSQ-2, as well as persistence, effort and boredom subscales. Epstein's TARGET strategies were applied to the experimental group during 12 weeks by specially trained coaches. The repeated measures MANOVA showed significant changes in all variables in the experimental group in post-test 1. Furthermore, these changes were maintained in most variables six months after the intervention (post-test 2). No significant changes were observed in the control group. Finally, the results are discussed and future lines of intervention are proposed.
\end{abstract}

Key words: Achievement Goal Theory, Motivation, Self-Determination Theory, Student-Athletes

Reviewers: Thelma Horn (Miami University, OH, USA)

Cliff Mallett (University of Queensland, Australia) 


\section{INTRODUCTION}

According to the World Health Organization, physical inactivity is the current fourth global mortality risk factor. The guide to increase the levels of physical activity created by this Institute includes the review of policies to provide the best programs, and the encouragement of research to assess physical inactivity in order to be able to promote actions for improvement ${ }^{1}$. Motivating children to be physically active is an urgent necessity. There is a need to understand what drives youngsters to sport.

The Achievement Goal Theory $\left(\mathrm{AGT}^{2}\right.$ ) has been a major theoretical framework used to understand motivation in different contexts, placing competence at the core of achievement. In sport settings, it has helped to understand the significance of achievement for athletes, and how this meaning influences their goals and their behaviours ${ }^{3}$. Within this theory, different environmental factors that direct individuals to construct competence have been studied under the term "motivational climate". Parents, peers and, specially, coaches have been researched as key agents in the construction of motivational climates based on the way they relate to sport and athletes ${ }^{4}$.

Research has distinguished two major motivational climates: mastery or task-involving and performance or ego-involving ${ }^{5}$. In mastery climates, success and failure are defined in terms of skill mastery and individual improvement. They are task-involving environments that emphasize the process of skill development, effort and personal improvement. They promote mastery-oriented individuals that try hard even when facing difficulties, show intrinsic interest in the different tasks, and persist over time ${ }^{6}$. Finally, they have been linked with confidence and enjoyment in physical activity settings ${ }^{4}$. In performance climates, success and failure are defined in normative terms, with an emphasis on outperforming teammates and opponents. They are ego-involving environments that focus on the outcomes and doing better than others. They promote performance-oriented individuals that are worried about being judged as better than their partners. Finally, they have been linked with anxiety or boredom in physical activity settings ${ }^{4}$.

Therefore, there has been a growing interest in creating mastery motivational climates when working with youngsters to maximize the benefits of those environments. Epstein ${ }^{7,8}$ identified six dimensions as fundamental in any classroom learning environment: task (design of activities), authority (location of decision-making), recognition (use of rewards), grouping (selection of working groups), evaluation (assessment criteria) and time (pace of instruction and learning). They form the acronym TARGET.

In a recent meta-analysis of research conducted on motivational climates in physical education, Braithwaite et al. ${ }^{4}$ linked mastery climates with affective outcomes such as attitudes ${ }^{9}$, boredom ${ }^{10}$, commitment/dedication ${ }^{11}$ and enjoyment $/$ satisfaction $^{10}$, behavioural outcomes such as health/fitness ${ }^{12}$ and motor skills ${ }^{13}$, and cognitive outcomes such as achievement goal orientations ${ }^{14}$, anxiety ${ }^{15}$, confidence/competence ${ }^{16}$, competitive and learning strategies ${ }^{17}$, motivational climate perceptions ${ }^{18}$, perceptions of ability and effort ${ }^{10}$. However, the TARGET strategies used had an overall small positive treatment effect for groups exposed to mastery motivational climates due to "lack of a validated and reliable measurement tool for each component of TARGET, different measurement tools for perceptions of climate, lack of standardized training policies and procedures for those administering interventions, and inequity and inconsistent evidence for many affective, behavioural, and cognitive outcomes" 4 .

Another major theoretical framework that is being widely used to study motivation in sport and physical activity is the Self-Determination Theory $\left(\mathrm{SDT}^{19}\right)$. Individuals are motivated to participate in sport by several reasons that lie in a continuum of autonomy from 
high to low levels of self-determination ${ }^{20}$. This theory identifies three major types of behavioural regulations: intrinsic motivation, extrinsic motivation, and amotivation. Intrinsic motivation has been defined as doing an activity for its inherent satisfaction, which represents the highest degree of self-determined motivation. Extrinsic motivation is evident when individuals perform an activity because they value its associated outcomes more than the activity itself. Finally, amotivation represents the absence of motivation to perform an activity ${ }^{21}$.

Based on this theory, Vallerand ${ }^{22}$ proposed a sequential and hierarchical model organized in four stages: social factors, psychological mediators, types of motivation and consequences. Each stage depends on the previous one and predicts the next, leading to final results or consequences: cognitive (e.g., concentration levels), affective (e.g., fun or boredom) and/or behavioural (e.g., persistence or effort). In sport scenarios, these consequences can be positive, pleasant and rewarding or tedious, boring and humiliating depending on the type of motivation promoted by the sport leader.

Vallerand ${ }^{22}$ hypothesized that the mentioned types of motivation are determined by the satisfaction of each individual's basic psychological needs: relatedness, competence and autonomy. Relatedness is the effort that individuals exert to interact and connect with others as well as their concern about others' wellbeing. Competence refers to a sense of being and feeling proficient in a particular environment. Autonomy reflects intentional, volitional, and self-endorsed behaviours. According to the SDT, fulfilment of these basic psychological needs would produce more self-determined motivational orientations. The satisfaction of these basic psychological needs depends on several sociocontextual factors: cooperation, the availability of autonomous election of tasks and behaviours ${ }^{23}$ and the learning climate structured by the instructor ${ }^{24}$. Cooperative learning should satisfy the need of relatedness since it has been linked to augmented relationship among peers ${ }^{25}$, a task orientation climate should enhance the perceived competence levels of the subjects ${ }^{26}$, and the openness of election (being able to choose, to have a saying on what is happening in the training session) should definitely make an impact on the individuals' autonomy ${ }^{27}$.

According to Braithwaite et al. ${ }^{4}$, most of the research conducted on motivational climate has been cross-sectional and limited to physical education. Ames ${ }^{24}$ believes that TARGET dimensions can also be applied to sport and physical activity settings because they share many structural features. To our knowledge, just a single field-intervention study in sport settings, using the TARGET framework, has been published. Theeboom et al. ${ }^{28}$ examined the effectiveness of a 3-week mastery oriented teaching program in a group of student-athletes. Results showed that the mastery-oriented group exhibited higher levels of enjoyment, intrinsic motivation and perceived competence and better motor skills. However, we must point out that the length of this intervention was very short (3 weeks).

Therefore, there has been a call for more empirical, intervention-based studies that would provide long-term assessment of the effects of a mastery climate on children/adolescents. Moreover, to provide reliable and practical information, researchers must assess long-termeffects of TARGET strategies on athletes' motivation using several timepoints. Another deficiency detected is that only a few studies have provided detailed information on time spent, as well as specific methods used to train coaches/teachers deliver the TARGET framework. There is a need to clarify this information.

Based on the aforementioned, the purpose of the present study was to assess the long-term effects that a manipulation of the motivational climate can cause over different psycho-social variables of a group of student-athletes in three timepoints: pre-intervention, immediately post-intervention, and six months after the end of the intervention. Our initial hypothesis was 
that a mastery training climate, structured by a coach following Epstein's TARGET strategies, will produce positive changes in several sociocontextual factors (cooperative learning, improvement and decision/election), basic psychological needs (social relations, competence and autonomy), self-determined motivation, and different behavioural affective consequences (persistence, effort and boredom) in a group of high school athletes.

\section{METHOD}

\section{PARTICIPANTS AND PROCEDURE}

The sample was composed by 283 student-athletes, football $(\mathrm{n}=150)$ and basketball $(\mathrm{n}=$ 133), with ages ranging from 14 to 18 years $(\mathrm{M}=13.54 \pm 1.31)$ participating in extracurricular sport at 6 different high schools. It was divided in two groups: Experimental ( $\mathrm{n}=143,45$ females and 98 males), and Control ( $\mathrm{n}=140,45$ females and 95 males). Each group was broken into ten subgroups: 10 basketball ( 6 males and 4 females) and 10 football (6 males and 4 females). In accordance with the recommendations of the University's ethics committee, written parental consent was obtained from all participants prior to data collection.

During 12 weeks (24, 1-hour sessions), an intervention program based in Epstein's TARGET strategies was applied to the experimental group by a total of 5 specially trained coaches (each one coached 2 teams). During the same amount of time, the control group carried out the same programmed training sessions without the implementation of the TARGET strategies. Coaches were randomly assigned to either the intervention or control groups. During the whole project, all groups worked independently from each other.

Prior to the intervention (pre), right after its conclusion (post 1), and 6 months later (post 2), all participants were asked to complete a specifically designed questionnaire. The first author administered the questionnaire pack, providing instructions and feedback to the athletes. To minimize the tendency of participants to provide socially desirable answers, researchers asked them to be totally honest and they were guaranteed complete anonymity and confidentiality.

\section{INTERVENTION PROGRAM}

The intervention program applied to the experimental group was elaborated adapting the model developed by Treasure ${ }^{29}$. This author identified those strategies that are consistent with promoting either ego or task achievement goals in a physical education setting, and organized them into Epstein's six TARGET areas. Several procedures suggested by Treasure and Roberts ${ }^{30}$ and Cecchini et al. ${ }^{11}$ to encourage task involving situations were also added. Below, we present the strategies for sport contexts that were used in this research project. Each strategy was applied in a wide range of learning/training activities.

Task. Coaches used open tasks that were presented globally. In this scenario, athletes had to solve a variety of problems in changing contexts. They adjusted their movements accordingly, trying to achieve short-term goals. Participants had few opportunities to compare their performance to their teammates, developing a sense for their own ability that did not depend on social comparison. Coaches focused their attention on the process and not on the product. They suggested lead-up activities based on each individual's achievement level, adapting them to fit each athlete's individual needs. To further promote learning, coaches transmitted the importance of work and effort.

Authority. Athletes actively participated in decision making processes during the different training sessions. To accomplish this goal, coaches used inductive instructional methods, mainly guided discovery and problem solving. Athletes were provided with choices 
regarding tasks (when and how to carry them) to increase their self-referenced perceptions.

Recognition. Individual progress was recognized and rewarded by the coaches in private to provide self-reference perceptions. Coaches treated all students equally and held similar expectations for all, independently of their initial level.

Grouping. Small cooperative training groups were established. They were formed in a flexible, heterogeneous way. Cooperative learning and team work was encouraged, trying to promote a working climate where the athletes could help each other learn tasks and abilities. Coaches tried to avoid rivalries among them.

Evaluation. Progress toward individual goals, personal improvement and participation was evaluated privately and self-referenced. To accomplish it, task skilfulness and personal progress criteria were used. These criteria were based on systematic observations of the conducts displayed by the participants.

Time. Athletes were allowed to take part in the decision-making process related to the pace of instruction and the time assigned to complete each task. With this time flexibility, individual differences in motor learning were considered.

Participating coaches were required to be professionally certified and have a minimum of 5 years of coaching experience (three years at the same high school). The ones randomly assigned to the experimental group also had to be willing to learn to apply the TARGET strategies attending a specific seminar prior to the beginning of the implementation phase. It consisted of 20 hours of theoretical and 10 hours of practical training, which included predesigned lessons to be practiced, discussed and analyzed. It was conducted by three of the researchers with more than 10 years of experience on the TARGET framework. During the implementation phase of the project, coaches had to attend another seminar (2-hour session every week) to share their views, their progress, the difficulties faced and their doubts with other participants and the university researchers. One training session per week of every team was videotaped and analyzed by the researches, who gave feedback to the coaches during the seminars based on it. Therefore, as suggested by Braithwaite et al. ${ }^{10}$, a combination of different strategies (training seminars, pre-designed sessions, and video analysis) was used to provide an adequate training to the participant coaches. Furthermore, the implementation of the intervention program on the experimental group was closely supervised by the researchers. They tried to establish fidelity of the TARGET approach through coaches' preparation, reflective practice and comparison between planned materials and observation of the implementation through video analysis of the training sessions ${ }^{31}$. The control groups were also supervised to avoid any influence of the TARGET strategies on their training sessions.

\section{MEASUREMENT}

Sociocontextual factors

Mastery climate was evaluated through the Cooperative Learning (e.g., "the teammates help you get better") and the Improvement subscales (e.g., "the teammates feel recognized when they improve") of the Perceived Motivational Climate in Sport-2 (PMCSQ-2 ${ }^{32}$ ). Athletes' perception of their participation (decision/election) was assessed through the Perceived Physical Education Class Climate subscale: (e.g., "Participants are often given the opportunity to plan their own activities") developed by Biddle et al.$^{33}$. All questions were preceded by the stem "In the training sessions...". All subscales demonstrated acceptable internal consistency scores with our sample: $.78, .81$ and .86 , respectively. 


\section{Psychological mediators}

The Spanish version of the Basic Psychological Needs in Exercise Scale (BPNES ${ }^{34}$ ) validated by Moreno et al. ${ }^{35}$ was used. It includes twelve items grouped in three subscales (four items each) to assess Autonomy (e.g., "The way I exercise is in agreement with my choices and interest"), Competence (e.g., "I feel I perform successfully the activities of my exercise program") and Relatedness (e.g., "My relationships with the people I exercise with are close"). The header sentence was "In the training sessions...". The internal consistency of each subscale with our sample was as follows: .72, .79 and .78, respectively.

\section{Motivation}

The Perceived Locus of Casualty Scale $\left(\mathrm{PLOC}^{36}\right)$ was used. Moreno et al. ${ }^{37}$ validated the scale for Spanish contexts. It consists of five subscales: Intrinsic Motivation (e.g., "because it is fun"), Identified Regulation (e.g., "because I want to learn sport skills"), Introjected Regulation (e.g., "because I want the coach to think that I am a good athlete"), External Regulation (e.g., "so the coach does not reprimand me") and Amotivation (e.g., "but I really feel that I am wasting my time"). Participants had to answer twenty items headed by the phrase "I participate in the training sessions...". Following guidelines provided by Vallerand ${ }^{38}$, a self-determination index (SDI) was calculated to reflect students' level of selfdetermination using this formula: $[(2 \mathrm{x}$ Intrinsic $\mathrm{M})+$ Identified R. $]-[(($ Introjected R. + External R.) / 2) + (2x Amotivation) $]$.

\section{Consequences}

In order to assess Persistence and Effort, an eight-item scale designed by Guan et al. ${ }^{39}$ was used. Four items measure Persistence (e.g., "When I have trouble performing some skills, I go back and practice") and the other four items measure Effort (e.g., "I put a lot effort into preparing for skill tests"). Boredom was evaluated using three items from Duda et al.'s scale $^{40}$ which measures affective responses (e.g., When we play, I generally wish for the game to end soon"). All subscales showed acceptable internal consistency scores with our sample: $.80, .75$ and .72 , respectively.

The item response format of all the questionnaires was a 5-point Likert-type scale that ranged from $1=$ "totally disagree" to $5=$ "totally agree".

\section{DATA ANALYSIS}

All data was analysed using SPSS 19.0 (IBM, Chicago, IL). Prior to the intervention, a MANOVA using group (experimental, control), gender (male, female) and sport (basketball, soccer) as independent variables and all the variables studied (Cooperative Learning, Improvement, Decision/Election, Social Relations, Competence, Autonomy, Persistence, Effort, SDI, and Boredom) as dependent variables was conducted to assess initial homogeneity among groups.

To assess if the trained coaches adhered to the training protocol established through the TARGET strategies, a $2 \times 3$ repeated measures MANOVA, using group as independent (between-subjects) variable and all sociocontextual factors (Cooperative Learning, Improvement and Decision/Election) as dependent (within-subjects) variables was conducted in three timepoints (pre, post-1 and post-2), because they assess student-athletes' perceptions of their coaches' conducts.

A third 2x3 repeated measures MANOVA, using group and time as independent variables and Social Relations, Competence, Autonomy, Persistence, Effort, SDI, and Boredom as dependent (within-subjects) variables was conducted to assess the effects of the TARGET program. 
Finally, linear contrast was performed to determine how each group changes (or not) along the three assessment timepoints (pre, post-1 and post-2). Independent and/or paired samples t-tests will be conducted, too.

\section{RESULTS}

\section{PRELIMINARY ANALYSES}

Pre-intervention differences between groups were examined through a multivariate analysis of variance (MANOVA). Group (control, experimental), sport (basketball, football), and gender were considered independent variables, and all the different factors measured (cooperative learning, improvement, decision/election, social relations, competence, autonomy, SDI, persistence, effort, boredom) dependent variables. No significant differences were found either in the different analyses conducted based on gender (Wilks' Lambda $=$ $.968, F_{(10,266)}=.82, p=.426$ ), sport (Wilks' Lambda $=.978, F_{(10,266)}=.61, p=.807$ ) or group (Wilks' Lambda $=.987, F_{(10,266)}=.34, p=.968$ ) or in the interaction group $\mathrm{x}$ gender (Wilks' Lambda $\left.=.988, F_{(10,266)}=.32, p=.976\right)$, group x sport (Wilks' Lambda $=.971, F_{(10}$, ${ }_{266)}=.80, p=.631$ ), gender $\mathrm{x}$ sport (Wilks' Lambda $=.978, F_{(10,266)}=.61, p=.807$ ) or gender $\mathrm{x}$ sport $\mathrm{x}$ group (Wilks' Lambda $=.973, F_{(10,266)}=.74, p=.686$ ). Therefore, groups could be considered homogeneous prior to the intervention.

\section{PRE-POST INTERVENTION DIFFERENCES}

To find out the possible effects generated by the intervention program, a 2 x 3 (group x time) repeated measures MANOVA was conducted using Cooperative Learning, Improvement and Decision/Election as dependent (within-subjects) variables. A significant multivariate effect emerged for the variables: group (Wilks' Lambda $=.572, F_{(3,279)}=69.54, p<.001, \eta=.43$ ) and time (Wilks' Lambda $\left.=.359, F_{(6,276)}=81.23, p<.001, \eta=.65\right)$ and the interaction: group x time (Wilks' Lambda $=.351, F_{(6,276)}=87.11, p<.001, \eta=.66$ ). Subsequent univariate analysis showed statistical significant differences in all variables (Figure 1): Cooperative learning $\left[F_{(2,562)}=261.40, p<.001, \eta=.48\right]$, Improvement $\left[F_{(2,562)}=164.42\right.$, $p<.001, \eta=.37]$ and Decision/Election $\left[F_{(2,562)}=400.35, p<.001, \eta=.59\right]$.

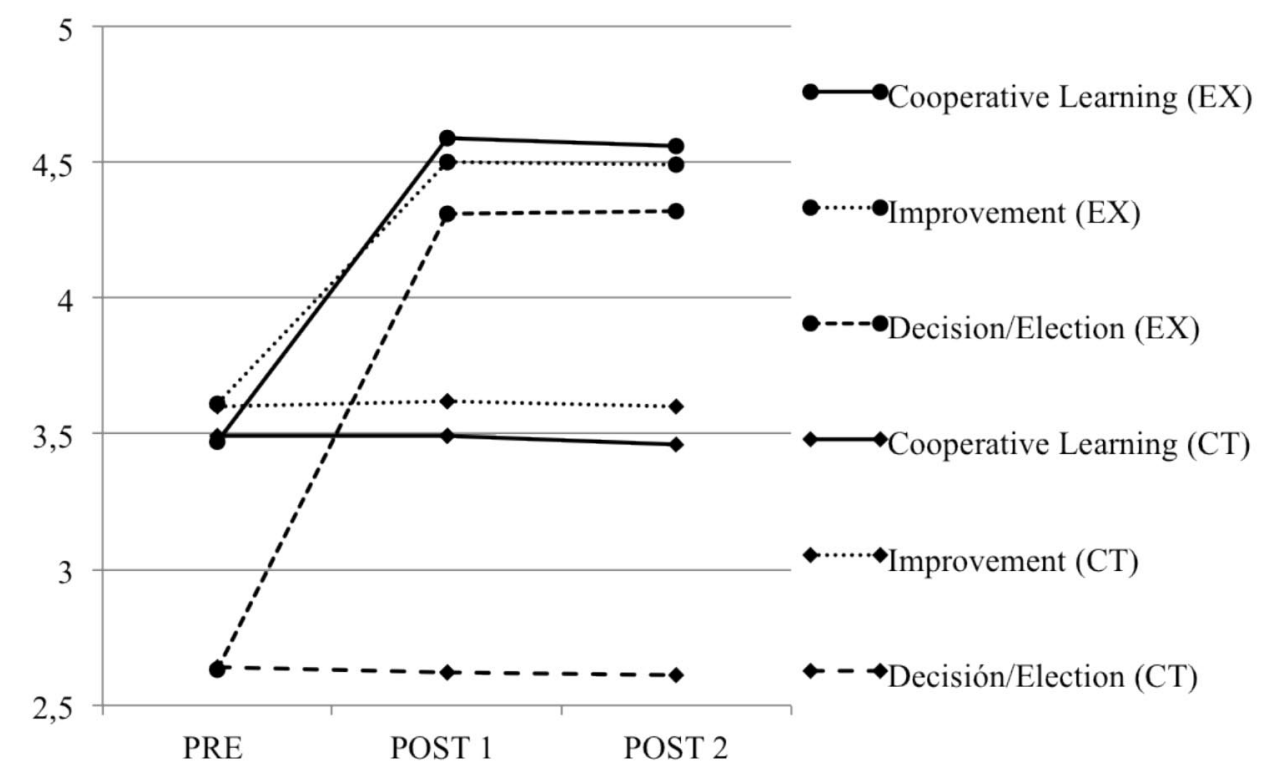

Figure 1. Contextual factors at Pre, Post 1 and Post 2 in the experimental and control groups 
A third $2 \times 3$ (group $\times$ time) repeated measures MANOVA was conducted using Social Relations, Competence, Autonomy, Persistence, Effort, and Boredom as dependent (withinsubjects) variables. A significant multivariate effect emerged for the variables: group (Wilks' Lambda $\left.=.618, F_{(7,275)}=24.32, p<.001, \eta=.38\right)$ and time (Wilks' Lambda $=.347, F_{(14,}$ ${ }_{268)}=36.03, p<.001, \eta=.65$ ) and the interaction: group $\mathrm{x}$ time (Wilks' Lambda $=.352, F$ $(14,268)=35.12, p<.001, \eta=.65)$. Subsequent univariate analysis showed statistical significant differences in all variables (Figures 2 and 3): Social relations $\left[F_{(2,562)}=46.39, p\right.$ $<.001, \eta=.14]$, Competence $\left[F_{(2,562)}=48.93, p<.001, \eta=.15\right]$, Autonomy $\left[F_{(2,562)}=\right.$ $395.86, p<.001, \eta=.58]$, SDI $\left[F_{(2,562)}=46.39, p<.001, \eta=.14\right]$, Persistence $\left[F_{(2.562)}=\right.$ $79.36, p<.001, \eta=.22]$, Effort $\left[F_{(2,262)}=86.66, p<.001, \eta=.24\right]$ and Boredom $\left[F_{(2,262)}\right.$ $=12.94, p<.001, \eta=.04]$.

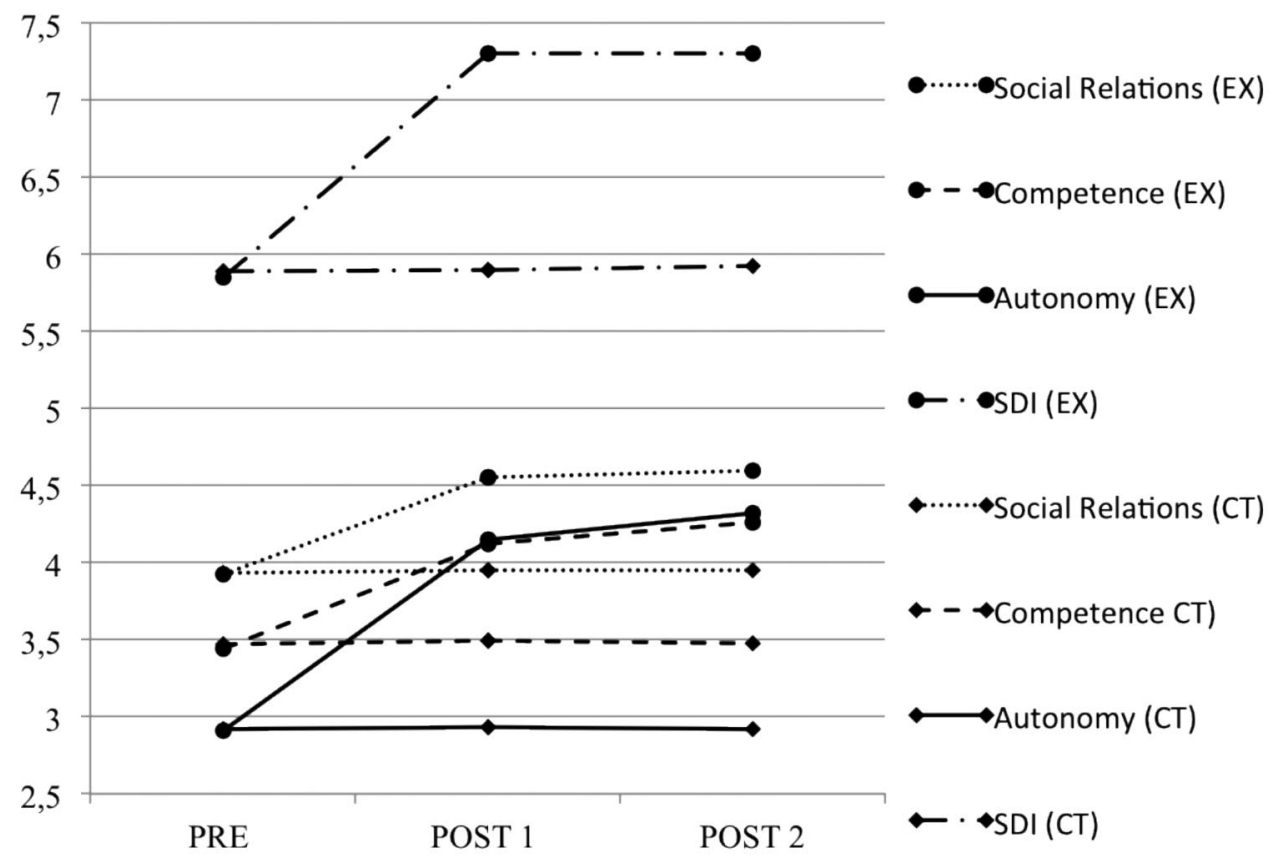

Figure 2. Basic Psychological Needs and SDI at Pre, Post 1 and Post 2 in the experimental and control groups

Results from both MANOVAS showed statistical significant differences $(\mathrm{p}<.001)$ between the control and the experimental groups in all variables after the intervention program in post- 1 and post-2. Results in the experimental group showed significant increases in all variables between pre and post-1, and between pre and post-2, except Boredom, which showed a significant decrease. Furthermore, significant differences between post- 1 and post 2 were found only in Cooperative learning $(\mathrm{p}<.05)$, SDI $(\mathrm{p}<.001)$ and Boredom $(\mathrm{p}<.05)$. There was a significant decrease in the first two variables and an increase in the last one. In the control group, no significant differences were found between pre-test, post-test 1 and post-test 2 in any variable (see Table 1). Finally, effect sizes were computed when significant differences were obtained among groups ${ }^{41}$. Results showed moderate to strong effects in all variables. 


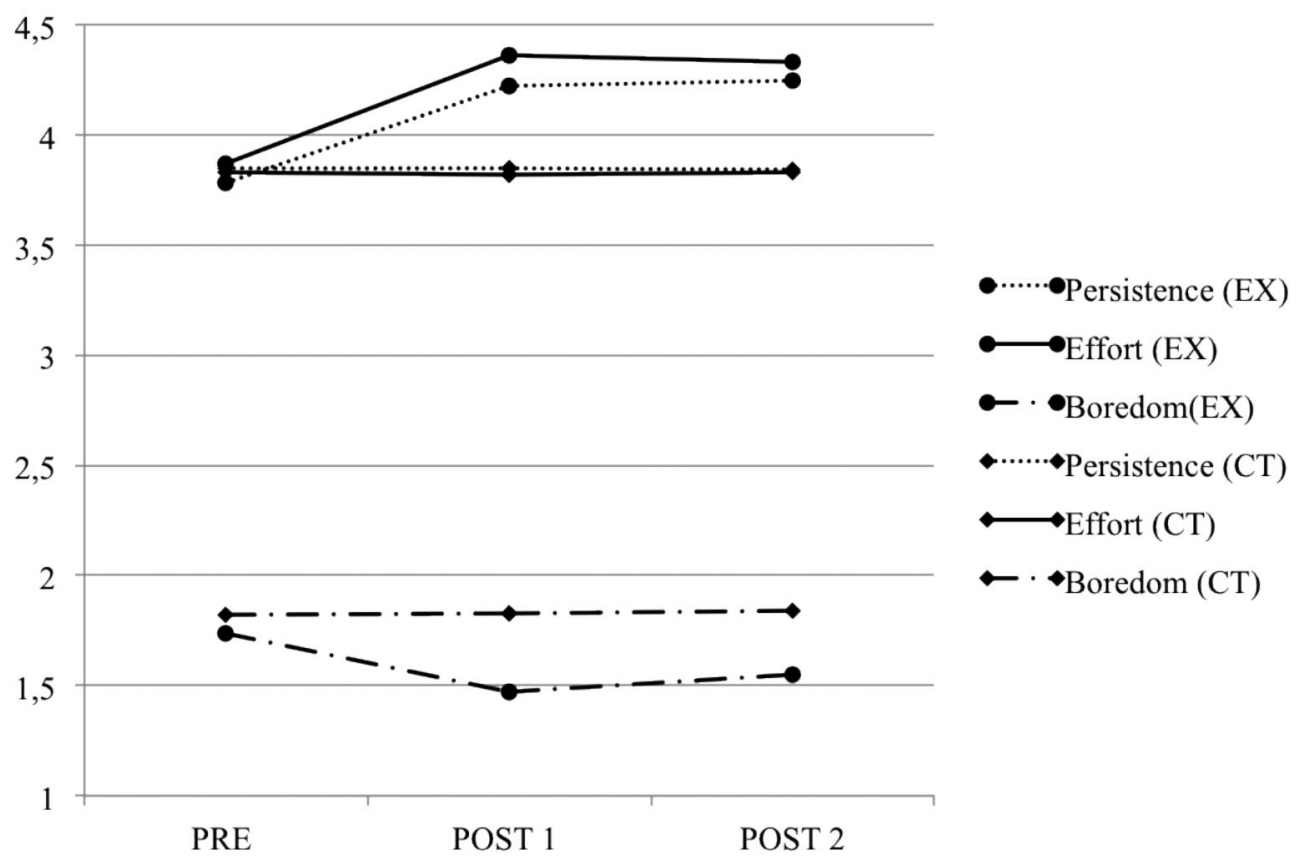

Figure 3. Motivational consequences at Pre, Post 1 and Post 2 in the experimental and control groups

\section{DISCUSSION}

The main goal of the present study was to assess the possible effects of manipulating the perceived motivational training climate of a group of student-athletes. Results revealed that a mastery-oriented climate, created by the coaches following Epstein's TARGET strategies, had a significant positive effect on the athletes' perceptions of cooperative learning, improvement, decision/election, social relations, competence, autonomy, self-determined motivation, persistence, effort and boredom. Results also showed that these positive effects of the intervention program were moderate to strong in all assessed variables. They were especially strong in the subjects' perceptions of their autonomy, their levels of decision/election, their improvement and their cooperative learning. Furthermore, all these positive effects were maintained 6 months after the conclusion of the intervention program in all the variables except cooperative learning, self-determined motivation, and boredom.

Our results showed that coaches can have a favourable bearing over their athletes' perceptions of the motivational climate in their training sessions. The strategies derived from the TARGET framework seemed to steer the construction of a task implication climate. The athletes were asked to cooperate with their teammates, to make decisions on what to do, how to do it, and when to do it, and evaluate their learning experiences according to selfreferenced criteria. This atmosphere seemed to have produced perceptions of a masteryoriented training climate, which generated an increase in cooperative learning among athletes. Horn et al. ${ }^{42}$ found that coach-initiated task-oriented climates are linked to high levels of perceived team cohesion, which could be promoted by cooperative work.

According to the $\mathrm{SDT}^{22,43}$, this increment in sociocontextual factors such as cooperative learning, improvement or decision/election has an influence in the subjects' basic 


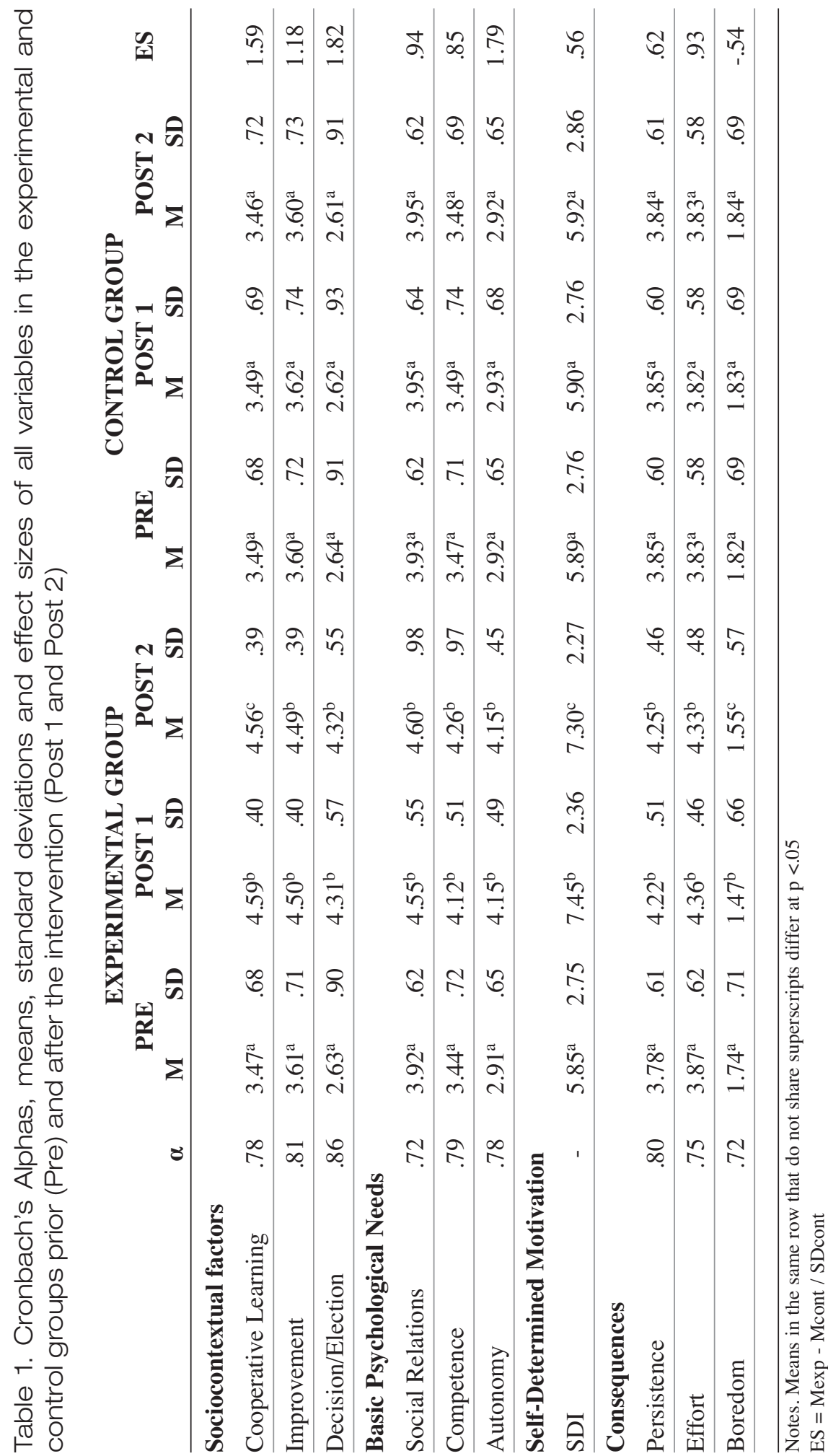


psychological needs. In our study, there was a significant increase in the athletes' levels of social relations, autonomy and perceived competence only in the experimental group. Almagro et al.$^{27}$ found that task-involving motivational climates positively predicted highschool athletes' basic psychological needs (autonomy, competence and relatedness). Similarly Boyce et $\mathrm{al}^{26}$ found that perceptions of a task-involving climate positively predicted perceived competence in a group of student-athletes.

According to Vallerand ${ }^{22}$, motivation is structured in a continuum that integrates different forms of motivation: from the total absence of motivation (amotivation) to the most selfdetermined motivation (intrinsic motivation). Our results showed that a mastery-oriented training climate, experienced in the experimental group, can increase the level of selfdetermined index (SDI) of a group of student-athletes. Similarly, Theeboom et al ${ }^{8}$ found that mastery motivational climates produced higher levels of intrinsic motivation and perceived competence in a group of student-athletes.

Finally, the existing literature ${ }^{22,43}$ has linked higher levels of self-determined motivation and positive cognitive, affective, and behavioural consequences. After experiencing a mastery-training climate, our sample of student-athletes reported increases in their selfdetermination index scores, but also their persistence and effort, and significantly decreased their boredom. In a group of football players, Van de Pol et al. ${ }^{44}$ found that effort and enjoyment were positively associated with perceived mastery climates. Seifriz et al. ${ }^{18}$ reported that perceptions of a mastery-oriented climate positively related to reported enjoyment and the belief that effort leads to achievement among a group of high-school basketball players. In a group of table tennis players, Santelices and Vinarao ${ }^{45}$ showed that the very high mastery climate created by the coaches valued effort and improvement, and the subjects reported having a positive experience with the sport. Our results reinforce all these findings and ideas. Therefore, this training atmosphere should be promoted, and coaches are a key element to do it.

However, what is truly remarkable in this research project is that most of the significant changes assessed in the post-test 1 were observed six months later. Results of the post-test 2 revealed that the majority of the positive outcomes produced by the TARGET training structure in the athletes' sociocontextual factors, basic psychological needs and consequences were maintained six months after the interruption of the intervention program. Only in three variables results changed significantly at post-test 2: cooperative learning and self-determination index decreased, while boredom increased among participants. However, these results were significantly better than those obtained prior to the intervention program (pre-test). A possible explanation for these results could be that the participant coaches integrated the training procedures learned during the research project into their training framework, and they continued applying them even after the end of the venture. These results also reinforce the training procedure followed to produce a significant change in the coaches working methodology in a relatively short period of time.

Although there is a personal predisposition that determines the probability to adopt a particular goal and to follow a particular behavioural pattern ${ }^{46}$, our results confirm that contextual factors, such as the perceived motivational climate, can act as agents of change. Certainly, athlete's perceptions, motivations, and behavioural consequences can be reconstructed through previously designed interventions. Coaches seem to play a significant role instilling positive experiences to the athletes. The strategies used in the intervention, based on Epstein's TARGET framework, have been proven as an adequate instrument for this purpose. Tasks were key elements in this framework. As explained earlier, they meant a challenge for the athletes to be solved, forcing them to work hard to be successful. Their 
design was adapted to fit the needs and possibilities of the athletes to awake their interest, increasing their persistence and effort. Our results reinforce this idea, since only the subjects in the experimental group increased significantly their levels of persistence and effort.

Within the TARGET structure, the participant coaches allowed the student-athletes to participate in the design of different tasks and activities, as well as other managerial decisions. This meant that the student-athletes' locus of control was not limited to the resolution of the problems raised by the coach. It was expanded to reach many other elements of the training context. It has been assessed that the higher the athlete's mastery climate is, the more internal his/her locus of control becomes ${ }^{47}$. Our results showed that a mastery training climate produced more autonomous and adaptive subjects. Perceptions of a more internal locus of control could have produced these effects in our student-athletes. In order to achieve these goals, it is necessary to shift the attention focus from the coaches' instruction to the athletes' learning. This shift demands from the coach to accept a new role: the role of helper, the role of teaching to learn. Similarly, the athletes should learn to self-direct their lives, to learn how to manage their time, and our results show that this apprenticeship should be the consequence of exercising their autonomy and their decision making in mastery climates structured around Epstein's TARGET strategies. Our results also indicate that this apprenticeship effort is based on feelings of improvement and competence, which foster individual progress, independently of the initial level or the place that each athlete holds in the group. Everybody can get better, therefore, everybody can be acknowledged. Competence feelings boosts personal satisfaction, as well as the interest for the sport, increasing the effort exerted in learning it.

Moreover, all information provided by the coach to improve the athlete's competence level should be self-referenced ${ }^{7,8}$. Every evaluation process should be constructed based on personal progress, and effort invested in learning. Likewise, the athletes should actively participate in their own evaluation process. Its purpose should not be to give them a certain grade, but to identify difficulties in the learning process and propose alternatives so each athlete can improve. This is why the learning pace should be adapted to fit each participant's individual characteristics (not all the participants start at the same level, nor they have the same capabilities). The program should be flexible and individualized.

Finally, our experience indicates that every learning experience should be shared. Helping others in their learning process is beneficial for both: the athlete that helps and the athlete that receives the help ${ }^{48}$. Team work and cooperative learning should be organized around groups that are flexible, dynamic and heterogeneous. Working as a team to reach a shared goal gives way to a greater active involvement and to more self-determined behaviours, because everybody has to share their views and their personal experiences. Success or failure is always shared. To reach success, every participant has to make an effort, get better and cooperate. Responsibility is not limited to the individual improvement. It also forces the athletes to help others in their learning experiences and to fill in their positions when needed. To help the team is to help each and every team member ${ }^{49}$.

No differences pertaining to gender or sport were observed in the effects of the program. Future studies should apply the TARGET framework in other sport settings and try to assess its effects on promoting active implication in physical and/or sport activities to mitigate the deep sedentary problem of our society.

The present study also holds several limitations. First, the data was obtained only from two sports (football and basketball). There is a need to test similar intervention programs in other sports, since each sport has a unique training context. Second, the age range of the subjects could be considered too large. The results could be different with other age groups. 
Third, previous studies ${ }^{4,50}$ have highlighted the need to use a multi-method approach (qualitative and quantitative) to measure motivational climate and its effects on different variables. Unfortunately, we have only used quantitative methods. Qualitative methods such as interviews or group discussions could provide a deeper understanding of the athletes' thoughts on the training climate created by their coaches. All these issues need to be addressed to be able to generalize the results obtained in this study.

\section{CONCLUSION}

The findings of the present study revealed that the coaching climate can be manipulated by the coaches, using Epstein's TARGET framework, to develop a task-involving training climate that produces a significant positive effect on student-athletes' sociocontextual factors such as cooperative learning, improvement and decision/election, their basic psychological needs such as social relations, competence and autonomy, their self-determined motivation, as well as several consequences such as persistence, effort and boredom. These positive effects were especially strong in this group of youngsters' perceptions of their autonomy, their levels of decision/election, their improvement and their cooperative learning during the training sessions.

Another major finding was that all the positive effects measured were maintained 6 months after the conclusion of the program. This could mean that the coaches continued using the TARGET framework even when they were not being supervised. Therefore, similar intervention programs could be used to produce significant changes in the coaches' working methodology.

To our knowledge, this is the first study to assess the long-term effects (pre-test, post-test 1, and post-test 2) of an intervention program using the TARGET framework in sport settings. It is expected that further studies should be conducted to test the effectiveness of similar programs.

\section{ACKNOWLEDGEMENTS}

This study has been conducted thanks to the I+D+I research grant \# DEP2012-31997 funded by the Ministry of Economy and Competitiveness of Spain.

\section{REFERENCES}

1. Armstrong, T., Bauman, A., Bull, F., Candeias, V., Lewicka, M., Magnussen, C., Persson, A. and Schoeppe, S., Implementation of the WHO Global Strategy on Diet, Physical Activity and Health. A Guide for Population-Based Approaches to Increasing Levels of Physical Activity, World Health Organization, Geneva, 2007.

2. Nicholls, J.G., Achievement Motivation: Conceptions of Ability, Subjective Experience, Task Choice, and Performance, Psychological Review, 1984, 91, 328-346.

3. Duda, J.L. and Hall, H., Achievement Goal Theory in Sport: Recent Extensions and Future Directions, in Singer R., Hausenblas H. and Janelle C., eds., Handbook of Sport Psychology. Wiley, New York, 2001, 417443.

4. Braithwaite, R., Spray, C.M. and Warburton, V.E. (2011). Motivational Climate Interventions in Physical Education: A Meta-Analysis, Psychology of Sport and Exercise, 12, 628-638.

5. Ames, C., Competitive, Cooperative and Individualistic Goal Structures: A Motivational Analysis, in Ames R. and Ames C., eds., Research on Motivation in Education: Student Motivation, Academic Press, New York, 1984, 177-207.

6. Roberts, G.C. and Treasure, D.C., Children in Sport, Sport Science Review, 1992, 1(2), 46-64.

7. Epstein, J., Effective Schools or Effective Students? Dealing with Diversity, in Haskins R. and MacRae B., eds., Policies for America's Public Schools. Ablex, Norwood, NJ, 1988, 89-126. 
8. Epstein, J., Family Structures and Student Motivation: A Developmental Perspective, in Ames C. and Ames R., eds., Research on Motivation in Education, Academic Press, New York, 1989, 259-295.

9. Christodoulidis, T., Papaioannou, A. and Digelidis, N, Motivational Climate and Attitudes Towards Exercise in Greek Senior High School: a Year-Long Intervention, European Journal of Sport Science, 2001, 1(4), 112 .

10. Duda, J. and Nicholls, J.G., Sport and Exercise Motivation: a Goal Perspectives Analysis, in Roberts G., ed., Motivation in Sport and Exercise, Human Kinetics, Champaign, IL, 1992, 57-91.

11. Cecchini, J.A., González, C., Carmona, M., Arruza, J., Escartí, A. and Balagué, G., The Influence of the Teacher of Physical Education on Intrinsic Motivation, Self-Confidence, Anxiety and Pre- and PostCompetition Mood States, European Journal of Sport Science, 2001, 1, 117-126.

12. Bowler, M., The Influence of the TARGET Motivational Climate Structures on Pupil Physical Activity Levels during Year 9 Athletics Lessons: Proceedings of the British Educational Research Association Annual Conference, Manchester, England, 2009.

13. Martin, E., Rudisill, M.E. and Hastie, P.A., Motivational Climate and Fundamental Motor Skill Performance in a Naturalistic Physical Education Setting, Physical Education and Sport Pedagogy, 2009, 14, 227-240.

14. Roberts, G.C., Treasure, D.C. and Balague, G., Achievement Goals in Sport: the Development and Validation of the Perception of Success Questionnaire, Journal of Sports Sciences, 1998, 16, 337-347.

15. Barkoukis, V., Tsorbatzoudis, H. and Grouis, G., Manipulation of Motivational Climate in Physical Education: Effects of a Seven-Month Intervention, European Physical Education Review, 2008, 4, 367-387.

16. Morgan, K. and Kingston, K., Development of a Self-Observation Mastery Intervention Programme for Teacher Education, Physical Education and Sport Pedagogy, 2008, 13, 109-129.

17. Morgan, K. and Carpenter, P., Effects of Manipulating the Motivational Climate in Physical Education Lessons, European Physical Education Review, 2002, 8, 207-229.

18. Seifritz, J.J., Duda, J.L. and Chi, L., The Relationship between Perceived Motivational Climate to Intrinsic Beliefs of Success about Basketball, Journal of Sport and Exercise Psychology, 1992, 17, 294-311.

19. Ryan, R.M. and Deci, E.L., Self-Determination Theory and the Facilitation of Intrinsic Motivation, Social Development and Well-Being, American Psychologist, 2000, 55, 68-78.

20. Lemyre, P.N., Treasure, D.C. and Roberts, G.C., Influence of Variability in Motivation and Affect on Elite Athlete Burnout Susceptibility, Journal of Sport and Exercise Psychology, 2006, 28, 32-48.

21. Deci, E.L. and Ryan, R.M., Intrinsic Motivation and Self-Determination in Human Behaviour, Plenum, New York, 1985.

22. Vallerand, R.J., Toward a Hierarchical Model of Intrinsic and Extrinsic Motivation, in Zanna M., ed., Advances in Experimental Social Psychology, Academic Press, New York, 1997, 271-360.

23. Vallerand, R.J. and Losier, G.F., An Integrative Analysis of Intrinsic and Extrinsic Motivation in Sport, Journal of Applied Sport Psychology, 1999, 11, 142-169.

24. Ames, C., Achievement Goals and the Classroom Climate, in Meece J. and Schunk D., ed., Student Perceptions in the Classroom, Erlbaum, Hillsdale, NJ, 1992, 327-348.

25. Fernandez-Rio, J., El Aprendizaje Cooperativo en el Aula de Educación Física para la Integración en el Medio Social. Análisis Comparativo con otros Sistemas de Enseñanza y Aprendizaje [Cooperative Learning in Physical Education for Social Inclusion. Comparative Analysis with other Teaching-Learning Structures], La Peonza, Valladolid, 2003.

26. Boyce, B.A., Gano-Overway, L.A. and Campbell, A.L., Perceived Motivational Climate's Influence on Goal Orientations, Perceived Competence, and Practice Strategies across the Athletic Season, Journal of Applied Sport Psychology, 2009, 21, 381-394.

27. Almagro, B.J., Sáenz-López, P., González-Cutre, D. and Moreno-Murcia, J.A., Clima Motivacional Percibido, Necesidades Psicológicas y Motivación Intrínseca como Predictores del Compromiso Deportivo en Adolescentes [Perceived Motivational Climate, Psychological Needs and Intrinsic Motivation as Predictors of Sport Commitment in Adolescent Athletes], International Journal of Sport Science, 2011, $7(25), 250-265$. 
28. Theeboom, M., De Knop, P. and Weiss, M.R., Motivational Climate, Psychological Responses, and Motor Skill Development in Children's Sport: a Field-Based Intervention Study, Journal of Sport and Exercise Psychology, 1995, 17, 294-311.

29. Treasure, D.C., A Social-Cognitive Approach to Understanding Children's Achievement Behavior, Cognitions, and Affect in competitive sport, Unpublished Doctoral Dissertation. University of Illinois at Urbana-Champaign, 1993.

30. Treasure, D. and Roberts, G., Cognitive and Affective Concomitants of Task and Ego Orientations during the Middle School Years, Journal of Sport and Exercise Psychology, 1994, 16, 15-28.

31. Parker, M.B. and Curtner-Smith, M.D., Health-Related Fitness in Sport Education and Multiactivity Teaching, Physical Education and Sport Pedagogy, 2005, 10(1), 1-18.

32. Newton, M.L., Duda, J.L. and Yin, Z., Examination of the Psychometric Properties of the Perceived Motivational Climate in Sport Questionnaire-2 in a Sample of Female Athletes, Journal of Sports Sciences, $2000,18,275-290$.

33. Biddle, S.J.H., Cury, F., Goudas, M., Sarrazin, P., Famose, J.P. and Durand, M., Development of Scales to Measure Perceived Physical Education Class Climate: A Cross-National Project, British Journal of Educational Psychology, 1995, 65, 341-358.

34. Vlachopoulos, S.P. and Michailidou, S., Development and Initial Validation of a Measure of Autonomy, Competence, and Relatedness: The Basic Psychological Needs in Exercise Scale, Measurement in Physical Education and Exercise Science, 2006, 10, 179-201.

35. Moreno, J.A., González-Cutre, D., Chillón, M. and Parra, N., Adaptación a la Educación Física de la Escala de las Necesidades Psicológicas Básicas en el Ejercicio [Adaptation of the BPNES to Physical Education], Revista Mexicana de Psicología, 2008, 25, 295-303.

36. Goudas, M., Biddle, S.J.H. and Fox, K.R., Perceived Locus of Causality, Goal Orientations, and Perceived Competence in School Physical Education Classes, British Journal of Educational Psychology, 1994, 64, 453-463.

37. Moreno, J.A., González-Cutre, D. and Chillón, M., Preliminary Validation in Spanish of a Scale Designed to Measure Motivation in Physical Education Classes: The Perceived Locus of Causality Scale, The Spanish Journal of Psychology, 2009, 12(1), 327-337.

38. Vallerand, R.J., A hierarchical Model of Intrinsic and Extrinsic Motivation in Sport and Exercise, in Roberts G.C., ed., Advances in Motivation in Sport and Exercise, Human Kinetics, Champaign, IL, 2001, 263-319.

39. Guan, J., Xiang, P., McBride, R. and Bruene, A., Achievement Goals, Social Goals, and Students' Reported Persistence and Effort in High School Physical Education, Journal of Teaching in Physical Education, 2006, $25,58-74$.

40. Duda, J.L., Fox, K., Biddle, S.J.H. and Armstrong, N., Children's Achievement Goals and Beliefs about Success in Sport, British Journal of Educational Psychology, 1992, 62, 313-323.

41. Glass, G.V., McGraw, B. and Smith, M.L., Meta-Analysis in Social Research, Sage, Beverly Hills, CA, 1981.

42. Horn, T.S., Byrd, M., Martin, E. and Young, C., Perceived Motivational Climate and Team Cohesion in Adolescent Athletes, Sport Science Review, 2012, 21(3-4), 25-49.

43. Deci, E.L. and Ryan, R.M., A Motivational Approach to Self: Integration in Personality, in: Deinstbier R., ed., Nebraska Symposium on Motivation. Perspectives on Motivation. University of Nebraska Press, Lincoln, NE, 1991, 237-288.

44. Van de Pol, P.K.C., Kavussanu, M. and Ring, C., Goal Orientations, Perceived Motivational Climate, and Motivational Outcomes in Football: A Comparison between Training and Competition Contexts, Psychology of Sport and Exercise, 2012, 13, 491-499.

45. Santelices, O.Y.S. and Vinarao, V.G., Perceived Motivational Climate of Female Table Tennis Athletes, International Journal of Table Tennis Sciences, 2010, 6, 1-17.

46. Dweck, C.S. and Legget, E.L., A Social-Cognitive Approach to Motivation and Personality, Psychological Review, 1988, 95(2), 256-273.

47. Gencer, E., The Relationship Between Locus of Control, Self-Esteem and Goal Orientation, Motivational Climate in Badminton Players. Science, Movement and Health, 2010, 10(2), 157-162. 
48. Dudley, B.S., Johnson, D.W. and Johnson, R.T., Using Cooperative Learning to Enhance the Academic and Social Experiences of Freshman Student Athletes, The Journal of Social Psychology, 1997, 137(4), 449-459.

49. Metzler, M.W., Instructional Models for Physical Education, Holcom Hathaway, Scottsdale, AZ, 2005.

50. Smith, R.E., Smoll, F.L. and Cumming, S.P., Motivational Climate and Changes in Young Athletes' Achievement Goal Orientations, Motivation and Emotion, 2009, 3, 173-183. 